\title{
Synthesis, Characterization and Biological Activity of Oxovanadium(IV) Complexes Containing $\alpha$-Amino Acid Schiff Bases and 5,6-Dimethyl-1,10-phenanthroline Ligands
}

\author{
(1) Md. Nur Amin Bitu, ${ }^{1}$ Md. Saddam Hossain, ${ }^{2}$ Md. Ali Asraf, ${ }^{1}$ (으 Md. Faruk Hossen, ${ }^{1}$ 이 Md. Kudrat-E-Zahan ${ }^{1, *}$
}

\author{
1 Department of Chemistry, University of Rajshahi, Rajshahi-6205, Bangladesh \\ 2 Department of Chemistry, Begum Rokeya University, Rangpur-5400, Bangladesh \\ * Corresponding author's e-mail address: kudrat.chem@ru.ac.bd \\ RECEIVED: April 29, 2021 * REVISED: June 9, 2021 * ACCEPTED: June 10, 2021
}

\begin{abstract}
Five oxovanadium(IV) complexes of the type [VO(L)(DPhen)], containing Schiff base derived from $\alpha$-amino acid, [where $L=$ 3-hydroxybenzaldehyde- $\alpha$-alanine (hb-Ala), 3-hydroxybenzaldehyde-DL-phenylalanine (hb-Phe), 3-hydroxybenzaldehyde-leucine (hb-Leu), 3-hydroxybenzaldehyde-glycine (hb-Gly) and 3-hydroxybenzaldehyde-DL-methionine (hb-Met) \& DPhen = 5,6-Dimethyl-1,10-phenanthroline] have been synthesized and characterized by some physicochemical properties, molar conductance, magnetic susceptibilities measurements, elemental analysis, UV-Visible, FT-IR and EIS-MS spectral studies. The molar conductance values evidenced the non-electrolytic nature of the complexes. The magnetic moment values of the complexes are in accordance with the $\mathrm{d}^{1}$ electronic configuration of the $\mathrm{V}^{\mathrm{I}} \mathrm{O}^{2+}$ moiety and indicates the paramagnetic behavior of the complexes. IR spectral data indicates the coordination of tridentate amino acid Schiff base ligands to the vanadyl $\left(\mathrm{VO}^{2+}\right)$ ion through $\mathrm{O}, \mathrm{N}$, O-donor. ESI-MS spectral study confirmed the proposed structure of the complexes. All the analytical data suggested that all the complexes possess to have distorted octahedral geometry. The complexes were screened for their antibacterial activity against four human pathogenic bacteria; two Gram positive Escherichia coli \& Pseudomonas aeruginosa and two Gram negative Staphylococcus aureus \& Bacillus cereus with Kanamycin (K-30) standard. The result shows that all the complexes have moderate to strong potential antibacterial activity against all the pathogenic bacteria.
\end{abstract}

Keywords: $\alpha$-amino acids, Schiff base, 5,6-dimethyl-1,10-phenanthroline, oxovanadium(IV) complexes, antibacterial activity.

\section{INTRODUCTION}

S CHIFF base ligands have a great importance to function as an excellent complexing agent that form various complexes with several transition and inner transition metals and has drawn the attention of many researchers. ${ }^{[1]}$ Schiff bases ligands and their transition metal complexes have a variety of applications including analytical, clinical, and biological applications as antibacterial, antifungal, anticancer, antiviral, and antitumor agents. ${ }^{[2-6]}$ The significance of metal ions is strongly established in biological systems. One of the most interesting features of metalcoordinated systems is the concerted spatial arrangement of the ligands around the metal ion. ${ }^{[7-9]}$ Among the various transition metal ions used in pharmacological studies, vanadium and its derivatives have been reported to possess different biological effects including antitumor, antimicrobial, antihypertension, anti-obesity, enhancement of oxygen affinity of hemoglobin and myoglobin etc. ${ }^{[10,11]}$ The discoveries of vanadium as an essential trace element for certain organisms makes its coordination chemistry as a topic of recent interest. ${ }^{[12-15]}$ Amino acids, a significant class of organicbased compounds may take part to prepare Schiff base by condensation of amine group $\left(\mathrm{NH}_{2}\right)$ with any carbonyl compound. They contain potential donor sites such as $\mathrm{COOH}$ and/or $\mathrm{NH}_{2}$ which have good ability to coordinate with the metal ions. It would be useful to fully understand the physiological function of such compounds by studying their coordination chemistry and behavior. Antimicrobial resistance (AMR) is one of the global health and development threat. It requires to find urgent alternative agent in order to achieve the Sustainable Development Goals (SDGs). 
Keeping these facts in mind, new oxovanadium(IV) complexes containing $\alpha$-amino acid Schiff bases and 5,6-Dimethyl-1,10-phenanthroline ligands were prepared, characterized and investigated their potential antibacterial activity.

\section{MATERIALS AND METHODS}

\section{Reagents and Chemicals}

All the reagents used were of analytical or chemically pure grade. Solvents were purified and dried according to standard procedures.

\section{Physical Measurements}

A Mettler PM-200 electronic balance was used to perform all the weighing operations. The melting point of all the synthesized metal complexes were recorded in an electro thermal melting point apparatus (model No.AZ6512). Conductivities of $1.0 \times 10^{-3} \mathrm{~mol} \mathrm{dm}^{-3}$ solutions of the complexes in DMF were measured at $30^{\circ} \mathrm{C}$ using a WPA CM 35 conductivity meter and a dip-cell with platinized electrodes. The SHERWOOD SCIENTIFIC Magnetic Susceptibility Balance was used to measure the magnetic moment value. Infrared spectra were recorded as $\mathrm{KBr}$ disc in a SIMADZU FTIR-8400 (Japan) infrared spectrophotometer, at the Central Science Laboratory of Rajshahi University, from $4000-225 \mathrm{~cm}^{-1}$. The absorbance of the complexes was recorded on Shimadzu Spectrophotometer (Model UV-1800). The ESI-MS spectra were performed using a Shimadzu-GeMs-Qp 100 EX mass spectrometer using the direct inlet system. Carbon, hydrogen and nitrogen analyses for the complexes were carried out by PerkinElmer 2400 organic elemental analyzer-II.

\section{General Method for the Preparation of the Oxovanadium(IV) Complexes of Type [VO(L) (DPhen)]}

Oxovanadium(IV) complexes were prepared by template method in which a mixture of $\alpha$-amino acids, $\alpha$-alanine (ala) (0.267 g, $3 \mathrm{mmol}$ ) / DL-phenylalanine (Phe) (0.495 g, $3 \mathrm{mmol}$ ) / leucine (leu) (0.393 g, $3 \mathrm{mmol}$ ) / glycine (gly) $(0.225 \mathrm{~g}, 3 \mathrm{mmol}) /$ DL-methionine (met) $(0.447 \mathrm{~g}, 3 \mathrm{mmol})$ and $\mathrm{NaOH}(0.12 \mathrm{~g}, 3 \mathrm{mmol})$ in $10 \mathrm{~mL}$ methanol were added to a methanolic solution of 3-hydorxybenzaldehyde (hb) $(0.366 \mathrm{~g}, 3 \mathrm{mmol})$ in a round bottom flask. The resulting solution was refluxed for 1 hour, followed by the addition of a methanolic solution of vanadyl sulfate $(0.489 \mathrm{~g}, 3$ $\mathrm{mmol}$ ). A light precipitate was obtained after refluxing the mixture for 1 hour. To this mixture, 5,6-Dimethyl-1,10phenanthroline (DPhen) $(0.625 \mathrm{~g}, 3 \mathrm{mmol}$ ) taken in $10 \mathrm{~mL}$ methanol was added. The solution on further refluxing for 1 hour gave a precipitate. The precipitate was filtered off on a Buchner funnel, washed with methanol and finally dried in a vacuum desiccator over anhydrous $\mathrm{CaCl}_{2} \cdot{ }^{[16]}$

The general synthetic method is shown below-

$\mathrm{VOSO}_{4}+\mathrm{L}+$ DPhen $\rightarrow[\mathrm{VO}(\mathrm{L})($ DPhen $)]$

where, L= 3-hydroxybenzaldehyde- $\alpha$-alanine (hb-Ala), 3hydroxybenzaldehyde-DL-phenylalanine (hb-Phe), 3-hydroxybenzaldehyde-leucine (hb-Leu), 3-hydroxybenzaldehydeglycine (hb-Gly), 3-hydroxybenzaldehyde-DL-methionine (hb-Met) and DPhen= 5,6-Dimethyl-1,10-phenanthroline.

\section{OXOVANADIUM(IV) COMPLEX OF $\alpha$-ALANINE [VO(hb-ALA)(DPhen)]}

0.812 g (58 \%); m.p. $219{ }^{\circ} \mathrm{C}$; Color: Dark brown; Physical state: Powder solid; Molar conductance $\left(\mathrm{Ohm}^{-1} \mathrm{~cm}^{2} \mathrm{~mol}^{-1}\right)$ : 12.0; Magnetic moment $\left(\mu_{\text {eff }} /\right.$ B.M.): 1.57 ; UV-Vis. $\left(\lambda_{\max } /\right.$ $\mathrm{nm}): 267-303,362,379 ; \mathrm{FT}-\mathrm{IR}\left(v_{\max } / \mathrm{cm}^{-1}\right): 3467(\mathrm{OH}), 1619$ $(\mathrm{C}=\mathrm{O}), 1544(\mathrm{C}=\mathrm{N}), 1315(\mathrm{C}-\mathrm{O}), 958(\mathrm{~V}=\mathrm{O}), 612(\mathrm{~V}-\mathrm{O}), 458$ (V-N); Anal. Calcd. mass fractions of elements, $w / \%$, for $\mathrm{VOC}_{24} \mathrm{H}_{21} \mathrm{~N}_{3} \mathrm{O}_{3}\left(M_{r}=466.38 \mathrm{~g} \mathrm{~mol}^{-1}\right)$ are $\mathrm{C} 61.81, \mathrm{H} 4.54, \mathrm{~N}$ 9.01; Found: C 60.93, H 4.29, N 9.15.

\section{OXOVANADIUM(IV) COMPLEX OF DL-PHENYLALANINE [VO(hb-Phe)(DPhen)]}

0.993 g (61\%); m.p. $193{ }^{\circ} \mathrm{C}$; Color: Orange; Physical state: Powder solid; Molar conductance $\left(\mathrm{Ohm}^{-1} \mathrm{~cm}^{2} \mathrm{~mol}^{-1}\right)$ : 15.1; Magnetic moment $\left(\mu_{\text {eff }} /\right.$ B.M.): 1.55 ; UV-Vis. $\left(\lambda_{\max } / \mathrm{nm}\right)$ : 268-302, 363, 377; FT-IR $\left(v_{\max } / \mathrm{cm}^{-1}\right): 3430(\mathrm{OH}), 1620$ $(\mathrm{C}=\mathrm{O}), 1541(\mathrm{C}=\mathrm{N}), 1312(\mathrm{C}-\mathrm{O}), 942(\mathrm{~V}=\mathrm{O}), 614(\mathrm{~V}-\mathrm{O}), 445$ (V-N); Anal. Calcd. mass fractions of elements, $w / \%$, for $\mathrm{VOC}_{30} \mathrm{H}_{25} \mathrm{~N}_{3} \mathrm{O}_{3}\left(M_{r}=542.48 \mathrm{~g} \mathrm{~mol}^{-1}\right)$ are $\mathrm{C} 66.42, \mathrm{H} 4.65, \mathrm{~N}$ 7.75; Found: C 64.97, H 4.38, N 7.63.

\section{OXOVANADIUM(IV) COMPLEX OF LEUCINE [VO(hb-Leu)(DPhen)]}

0.946 g (62\%); m.p. $223^{\circ} \mathrm{C}$; Color: Brown; Physical state: Powder solid; Molar conductance $\left(\mathrm{Ohm}^{-1} \mathrm{~cm}^{2} \mathrm{~mol}^{-1}\right)$ : 10.0; Magnetic moment ( $\mu_{\text {eff }} /$ B.M.): 1.54 ; UV-Vis. $\left(\lambda_{\max } / \mathrm{nm}\right)$ : 268-301, 365, 375; FT-IR $\left(v_{\max } / \mathrm{cm}^{-1}\right): 3456(\mathrm{OH}), 1620$ $(\mathrm{C}=\mathrm{O}), 1536(\mathrm{C}=\mathrm{N}), 1311$ (C-O), $957(\mathrm{~V}=\mathrm{O}), 616(\mathrm{~V}-\mathrm{O}), 457$ (V-N); Anal. Calcd. mass fractions of elements, $w / \%$, for $\mathrm{VOC}_{27} \mathrm{H}_{27} \mathrm{~N}_{3} \mathrm{O}_{3}\left(M_{r}=508.46 \mathrm{~g} \mathrm{~mol}^{-1}\right)$ are $\mathrm{C} 63.78, \mathrm{H} 5.35, \mathrm{~N}$, 8.26; Found: C 63.17, H 4.98, N 8.17.

\section{OXOVANADIUM(IV) COMPLEX OF GLYCINE [VO(hb-Gly)(DPhen)]}

0.909 g (67\%); m.p. $225^{\circ} \mathrm{C}$; Color: Reddish brown; Physical state: Powder solid; Molar conductance $\left(\mathrm{Ohm}^{-1} \mathrm{~cm}^{2} \mathrm{~mol}^{-1}\right)$ : 16.1; Magnetic moment $\left(\mu_{\text {eff }} /\right.$ B.M. $): 1.58$; UV-Vis. $\left(\lambda_{\max } /\right.$ $\mathrm{nm}): 269-302,362$, 376; FT-IR $\left(v_{\max } / \mathrm{cm}^{-1}\right): 3426(\mathrm{OH}), 1642$ $(\mathrm{C}=\mathrm{O}), 1535(\mathrm{C}=\mathrm{N}), 1312(\mathrm{C}-\mathrm{O}), 963(\mathrm{~V}=\mathrm{O}), 617(\mathrm{~V}-\mathrm{O}), 463$ $(\mathrm{V}-\mathrm{N})$; Anal. Calcd. mass fractions of elements, $w / \%$, for 
$\operatorname{VOC}_{23} \mathrm{H}_{19} \mathrm{~N}_{3} \mathrm{O}_{3}\left(M_{r}=452.36 \mathrm{~g} \mathrm{~mol}^{-1}\right)$ are C 61.07, $\mathrm{H} 4.23, \mathrm{~N}$ 9.29; Found: C 60.87, H 4.19, N 9.08.

\section{OXOVANADIUM(IV) COMPLEX OF DL-METHIONINE [VO(hb-Met)(DPhen)]}

0.979 g (62\%); m.p. $195{ }^{\circ} \mathrm{C}$; Color: Brown; Physical state: Powder solid; Molar conductance $\left(\mathrm{Ohm}^{-1} \mathrm{~cm}^{2} \mathrm{~mol}^{-1}\right)$ : 10.0 ; Magnetic moment $\left(\mu_{\text {eff }} /\right.$ B.M. $): 1.70$; UV-Vis. $\left(\lambda_{\max } / \mathrm{nm}\right)$ : 271-306, 365, 383; FT-IR $\left(v_{\max } / \mathrm{cm}^{-1}\right): 3423(\mathrm{OH}), 1637$ $(\mathrm{C}=\mathrm{O}), 1538(\mathrm{C}=\mathrm{N}), 1312(\mathrm{C}-\mathrm{O}), 959(\mathrm{~V}=\mathrm{O}), 616(\mathrm{~V}-\mathrm{O}), 451$ $(\mathrm{V}-\mathrm{N})$; Anal. Calcd. mass fractions of elements, $w / \%$, for $\mathrm{VOC}_{26} \mathrm{H}_{25} \mathrm{~N}_{3} \mathrm{O}_{3} \mathrm{~S}\left(M_{r}=526.50 \mathrm{~g} \mathrm{~mol}^{-1}\right)$ are $\mathrm{C} 59.31, \mathrm{H} 4.79, \mathrm{~N}$ 7.98; Found: C 59.08, H 4.67, N 7.83.

\section{RESULTS AND DISCUSSION}

\section{Solubility}

All the complexes are soluble in dimethylsulfoxide (DMSO) and dimethylformamide (DMF) but insoluble in common organic solvents such as methanol, ethanol, chloroform, benzene etc.

\section{Elemental Analysis and Conductivity Measurement}

The molar conductance of the complexes was measured in DMF $\left(10^{-3} \mathrm{M}\right.$ solution) at $30^{\circ} \mathrm{C}$. The molar conductance values (10.0 to $16.1 \Omega^{-1} \mathrm{~cm}^{2} \mathrm{~mol}^{-1}$ ) indicate that all the complexes are non-electrolytic in nature. Their structures have been proposed based on the elemental analysis, conductivity and magnetic susceptibility measurements, IR spectral and UV-Visible spectral analysis. ${ }^{[17]}$ Also, the analytical data are in good agreement with their proposed empirical formula.

\section{Magnetic Moment and Electronic Spectra}

A Sherwood Scientific magnetic susceptibility balance was used to measure the magnetic susceptibility of the complexes at room temperature $(303 \mathrm{~K}) .{ }^{[18]}$ The observed values of effective magnetic moment ( $\mu_{\text {eff }}$ ( 1.54 to $1.70 \mathrm{BM}$ ) at room temperature indicated that all the complexes are paramagnetic in nature. The electronic spectra of the complexes were recorded in DMSO in the wavelength of 200-800 $\mathrm{nm}$ range. All the complexes exhibit a shoulder at $\sim 378 \mathrm{~nm}$ due to ligand-to-metal charge-transfer (LMCT, $\mathrm{PhO}^{-} \rightarrow \mathrm{V}$ ) transition, and the remaining bands appearing in the UV region are assignable to the intraligand transitions. ${ }^{[19]}$ All complexes display bands in between 267$306 \mathrm{~nm}$ which are assignable to the $\pi \rightarrow \pi^{*}$ transition. [16]

\section{FT-IR Spectral Studies}

The IR spectral data of the complexes show a broad band in the region of $3423-3467 \mathrm{~cm}^{-1}$ which is possibly due to the $\mathrm{v}(\mathrm{O}-\mathrm{H})$ bands of hydrated water molecule in the complexes. ${ }^{[20]}$ The presence of $v(C=O)$ band and $v(C-O)$ band in the complexes indicated by the frequency in between 1619-1642 $\mathrm{cm}^{-1}$ and 1311-1315 $\mathrm{cm}^{-1}$ respectively which are significantly lower than the values for respective bands of uncoordinated amino acids. Further, the appearance of $\mathrm{v}(\mathrm{V}-\mathrm{O})$ stretching modes in the range $612-617 \mathrm{~cm}^{-1}$ confirms the coordination of carboxylate ion to the central metal ion. ${ }^{[21]}$ The absence of frequency at $\sim 3600 \mathrm{~cm}^{-1}$ for the phenolic-OH indicates the coordination of phenolic oxygen to vanadyl ion. The bands appeared in between $1535-1544 \mathrm{~cm}^{-1}$ may be assigned to $\mathrm{v}(\mathrm{C}=\mathrm{N})$ stretching frequency suggesting the coordination of the azomethine nitrogen to the $\mathrm{VO}^{2+}$ moiety. The
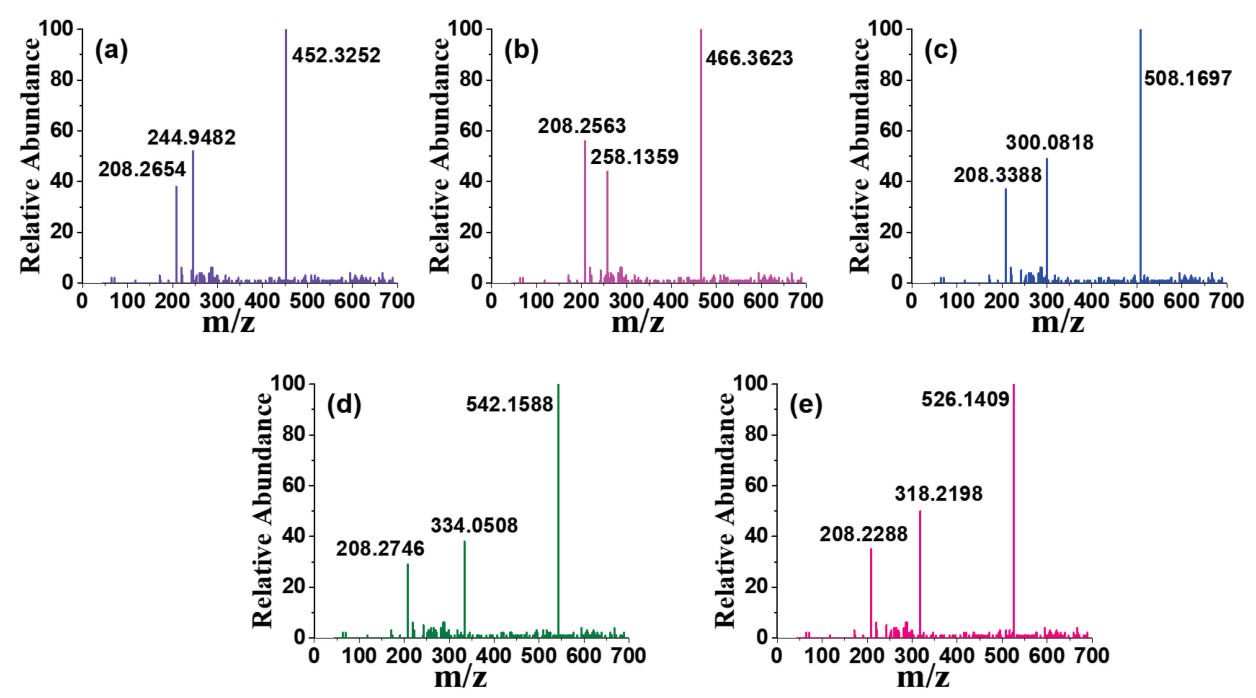

Figure 1. ESI-MS spectrum of the complexes; (a) [VO(hb-Gly)(Dphen)]; (b) [VO(hb-Ala)(Dphen)]; (c) [VO(hb-Leu)(Dphen)]; (d) [VO(hb-Phe)(Dphen)];(e) [VO(hb-Met)(Dphen)]. 


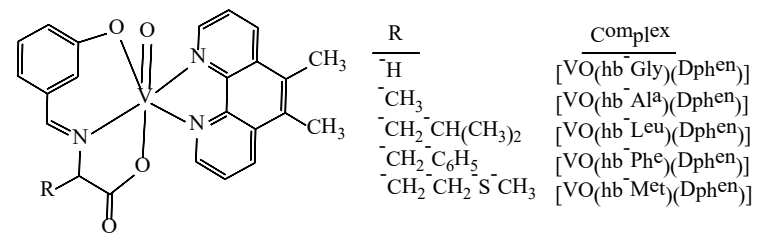

Figure 2. Proposed structure of the Oxovanadium(IV) complexes.

coordination of azomethine nitrogen and heterocyclic nitrogen is further evident by the appearance of $\mathrm{v}(\mathrm{V}-\mathrm{N})$ modes in the $445-463 \mathrm{~cm}^{-1}$ region. ${ }^{[22]}$

\section{ESI-MS Spectral Studies}

ESI-MS (Electrospray ionization mass) spectroscopy is another important technique used for the analysis of thermally fragile and high-molecular-weight compounds. In this method, a solution of the analyte is pumped through a high-voltage capillary and the ejected droplet is transferred into the gaseous ion phase before passing through a mass spectrometric analyzer. ESI-MS is also a soft ionization technique which provides a complete picture of the absolute molecular mass of the analyte. The ESI-MS spectra (Figure 1) of the metal oxo complexes confirm the proposed formula of the synthesized metal complexes.

On the basis of the elemental analysis, conductivity measurements, magnetic moment data, spectroscopic studies and literature review the structure of the complexes could be illustrated as shown in Figure 2.

\section{ANTIBACTERIAL ACTIVITY OF THE COMPLEXES}

Antibacterial activities of the complexes are investigated by using the highly adoptable disc diffusion method. ${ }^{[23,24]}$ The complexes (50 $\mu \mathrm{g} /$ disc in DMSO solution) were screened for their antibacterial activity against four human pathogenic bacteria; two Gram positive Escherichia coli \& Pseudomonas aeruginosa and two Gram negative Staphylococcus aureus \& Bacillus cereus with Kanamycin (K-30) standard. [25-28] Overtone's concept and Tweedy's chelation theory can explain the greater activity of the complexes. ${ }^{[29]}$ The significant antibacterial activity of metal complexes is due to the fact that only lipid-soluble materials making lipo-solubility, which is a main control factor for antibacterial activity. The polarity of metal ions is more reduced, due to overlap and the partial sharing of positive charge of the metal ion with the orbitals of the donor groups of the ligands. The metal ions are therefore, easily be adsorbed on the surface of the cell wall of the organisms and able to disrupt the respiratory process of the cells and blocks protein synthesis and consequently, limits the additional growth of organisms. Besides this, the substituent methyl/benzyl group plays a vital role to increase the lipophilic nature of the metal complexes that is the reason for remarkable antibacterial activity and other factors like solubility, coordinating sites, the geometry of complexes, steric, concentration, and hydrophobicity having considerable influence on the antibacterial potency. ${ }^{[29-31]}$ The result

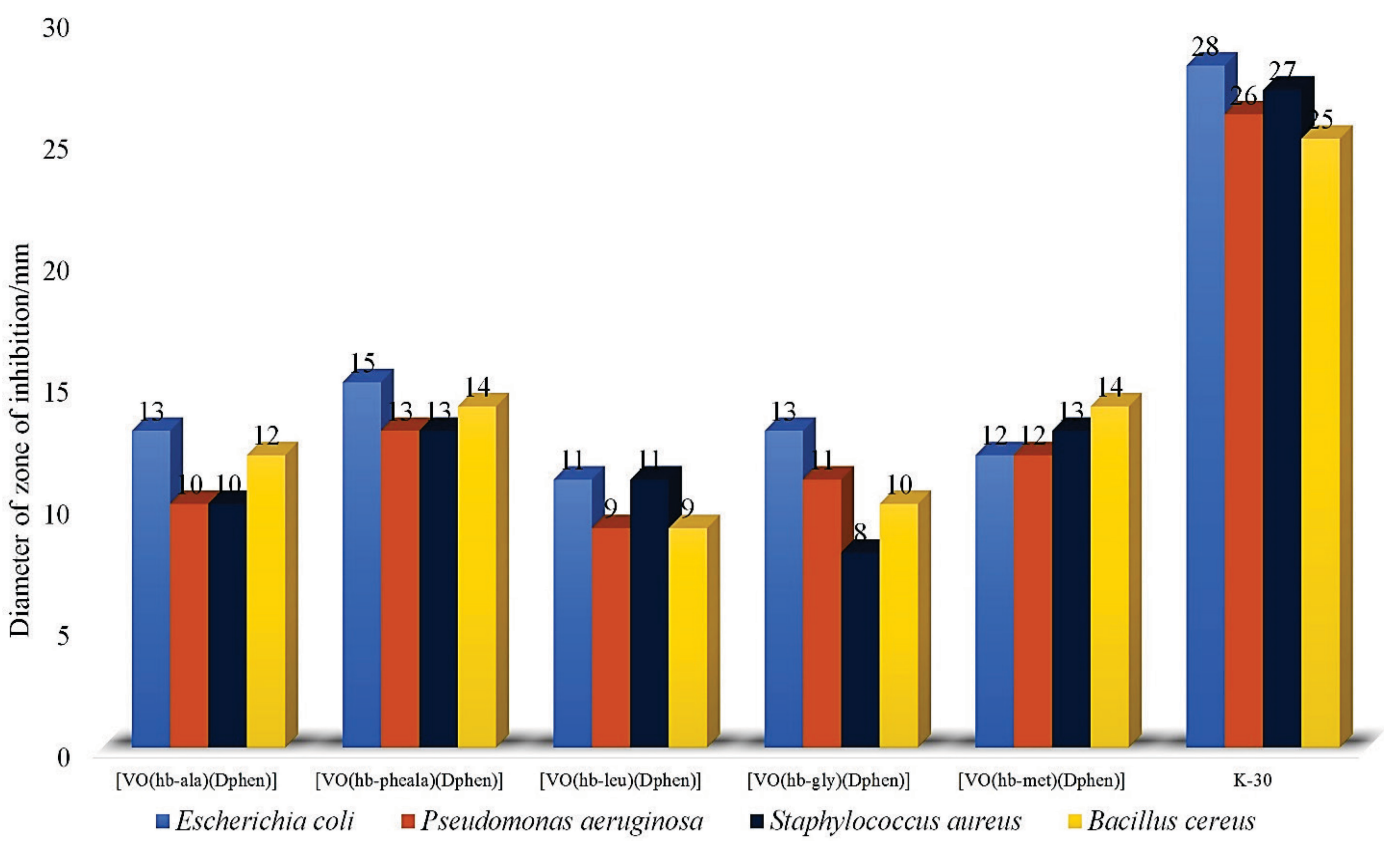

Figure 3. Graphical representation of the antibacterial activity of the complexes against Escherichia coli, Pseudomonas aeruginosa, Staphylococcus aureus and Bacillus cereus. 
shows that all the complexes have moderate to strong potential antibacterial activity against all the pathogenic bacteria. [VO(hb-Met)(Dphen)] and [VO(hb-Phe)(Dphen)] complexes showed highest activity compared to other complexes which is consistent with the above mentioned theory. The result is graphically represented in Figure 3 .

\section{CONCLUSIONS}

The $\mathrm{VO}^{2+}$ complexes of $\mathrm{O}, \mathrm{N}, \mathrm{O}$-donor $\alpha$-amino acid Schiff bases and 5,6-Dimethyl-1,10-phenanthroline have been synthesized and characterized. The molar conductance value and magnetic moment value reveal that the complexes are non-electrolytic and paramagnetic in nature. The magnetic moment values of the complexes are in accordance with the $d^{1}$ electronic configuration of the $\mathrm{V}^{\mathrm{IV}} \mathrm{O}^{2+}$ moiety. FT-IR spectral data indicates the coordination of tridentate amino acid Schiff base ligands to the vanadyl $\left(\mathrm{VO}^{2+}\right)$ ion. Thus, on the basis of physicochemical properties, elemental analysis, conductivity measurements, magnetic moment values, spectroscopic studies and literature review, the structure of the complexes (Figure 2) may be proposed as distorted octahedral geometry with $\mathrm{VO}_{3} \mathrm{~N}_{3}$ coordination environment. All the complexes were screened for their antibacterial activity against four human pathogenic bacteria - Escherichia coli, Pseudomonas aeruginosa, Staphylococcus aureus and Bacillus cereus with Kanamycin (K-30) standard. The result shows that all the complexes have moderate to strong potential antibacterial activity against all the tested pathogens.

Acknowledgment. The authors are thankful to the Chairman, Department of Chemistry, University of Rajshahi, Rajshahi6205, Bangladesh for the laboratory facilities.

Supplementary Information. Supporting information to the paper is attached to the electronic version of the article at: https://doi.org/10.5562/cca3775.

PDF files with attached documents are best viewed with Adobe Acrobat Reader which is free and can be downloaded from Adobe's web site.

\section{REFERENCES}

[1] M. N. A. Bitu, M. S. Hossain, A. A. S. M. Zahid, C. M. Zakaria, M. Kudrat-E-Zahan, American J. of Het. Chem. 2019, 5, 11-23.

[2] L. Cheng, J. Tang, H. Luo, X. Jin, F. Dai, J. Yang, Y. Qian, X. Li, B. Zhou, Bioorg. Med. Chem. Lett. 2010, 20, 2417-2420.

https://doi.org/10.1016/j.bmcl.2010.03.039

[3] M. S. Hossain, S. Sarker, A. S. M. Elias Shaheed, M. M. Hossain, A. Alim-Al-Bari, M. R. Karim, C. M. Zakaria, M. Kudrat-E-Zahan, Chem. \& Bio. Eng. 2017, 2, 41-50.
[4] X. Ran, L. Wang, D. Cao, Y. Lin, J. Hao, Appl. Organomet. Chem. 2010, 25, 9-15. https://doi.org/10.1002/aoc.1680

[5] Kudrat-E-Zahan, S. Hossain, M. M. Haque, L. A. Banu, M. A. Matin, N. A. Bitu, A. Habib, Ashrafuzzaman, N. Uddin, M. S. Islam, Biochem. \& Mol. Bio. 2019, 4, 3541. https://doi.org/10.11648/j.bmb.20190403.11

[6] G. T. Rahman, M. Kudrat-E-Zahan, M. M. Haque, M. M. Alam, M. A. Farooque, Sci. J. of Chem. 2015, 3, 91-94.

[7] X. Tai, X. Yin, Q. Chen, M. Tan, Molecules 2003, 8, 439-443.

https://doi.org/10.3390/80500439

[8] J. Vančo, O. Švajlenová, E. Račanská, J. Muselík, J. Valentova, J. Trace Elem. Med. Biol., 2004, 18, 155161. https://doi.org/10.1016/j.jtemb.2004.07.003

[9] J. A. Obaleye, J. F. Adediji, M. A. Adebayo, Molecules 2011, 16, 5861-5874.

https://doi.org/10.3390/molecules16075861

[10] P. Noblía, E. J. Baran, L. Otero, P. Draper, H. Cerecetto, M. González, O. E. Piro, E. E. Castellano, T. Inohara, Y. Adachi, H. Sakurai, D. Gambino, Eur. J. Inorg. Chem. 2004, 2, 322-328.

https://doi.org/10.1002/ejic.200300421

[11] P. Pattanayak, J. L. Pratihar, D. Patra, S. Mitra, A. Bhattacharyya, H. M. Lee, S. Chattopadhyay, Dalton Trans. 2009, 46, 6220-6230. https://doi.org/10.1039/b903352a

[12] N. D. Chasteen, Vanadium in Biological Systems, Kluwer Academic Publishers, Dordrecht, The Netherlands, 1990.

[13] R. R. Eady, Coord. Chem. Rev. 2003, 237, 23-30. https://doi.org/10.1016/S0010-8545(02)00248-5

[14] K. H. Thompson, C. Orvig, Coord. Chem. Rev. 2001, 219, 1033-1053.

https://doi.org/10.1016/S0010-8545(01)00395-2

[15] H. Michibata, N. Yamaguchi, T. Uyama, T. Ueki, Coord. Chem. Rev. 2003, 237, 41-51.

[16] P. K. Sasmal, A. K. Patra, M. Nethaji, A. R. Chakravarty, Inorg. Chem. 2007, 46, 11112-11121. https://doi.org/10.1021/ic7011793

[17] S. I. Al-Resayes, M. Shakir, A. Abbasi, K. M. Y. Amin, A. Lateef, Spectrochim. Acta, Part A 2012, 93, 86-94. https://doi.org/10.1016/j.saa.2012.02.099

[18] A. Kriza, L. Mitu, N. Stanica, Rev. Chim. (Bucharest) 2005, 56, 137-140.

[19] S. K. Dutta, S. B. Kumar, S. Bhattacharyya, E. R. T. Tiekink, M. Chaudhury, Inorg. Chem. 1997, 36, 4954-4960.

[20] M. R. Maurya, S. Khurana, C. Schulzke, D. Rehder, Eur. J. Inorg. Chem. 2001, 3, 779-788.

[21] S. L. Dutta, R. A. Lal, Indian. J. Chem. Sect. A 1988, 27 , 225-234. 
[22] S. Singh, V. Chakravorty, C. K. Das, Indian. J. Chem. Sect. A, 1989, 28, 256.

https://doi.org/10.1016/0093-691X(89)90664-X

[23] N. A. Bitu, S. Hossain, N. Islam, A. Kader, M. S. Islam, M. M. Haque, F. Hossen, A. Asraf, R. K. Mohapatra, Kudrat-E-Zahan, Rus. J. of Gen. Chem. 2020, 90, 15531557. https://doi.org/10.1134/S1070363220080253

[24] K. A. Elachi, M. S. Hossain, M. N. A. Bitu, A. A. S. M. Zahid, R. K. Mohapatra, M. A. Mannan, C. M. Zakaria, M. Kudrat-E-Zahan, J. of Chem., Bio. and Phys. Sci. Sect. A: Chemical Sciences 2019, 9, 201.

[25] M. M. Ali, M. N. A. Bitu, M. S. Hossain, M. F. Hossen, M. A. Asraf, M. A. Farooque, M. Kudrat-E-Zahan, Asian J. of Chem. Sci. 2020, 8, 15-21. https://doi.org/10.9734/ajocs/2020/v8i119032

[26] M. E. Haque, M. Z. Rahman, M. M. Pervin, M. H. Kabir, M. S. Imran, K. M. K. B. Ferdaus, M. Khalekuzzaman, Pak. J. of Bio. Sci. 2005, 8, 1746-1750.
[27] M. M. Ali, M. N. A. Bitu, M. S. Hossain, M. F. Hossen, M. A. Asraf, M. A. Farooque, M. M. Hossain, M. Kudrat-E-Zahan, Asian J. of Chem. Sci. 2020, 8, 1-7. https://doi.org/10.9734/ajocs/2020/v8i219036

[28] M. M. Ali, M. N. A. Bitu, M. S. Hossain, M. F. Hossen, M. A. Asraf, M. M. Haque, M. A. Farooque, M. KudratE-Zahan, New Mat., Com. and App. 2020, 4, 173.

[29] M. N. Patel, P. B. Pansuriya, P. A. Parmar, D. S. Gandhi, Pharma. Chem. J. 2008, 42, 687-692. https://doi.org/10.1007/s11094-009-0214-2

[30] K. Venkateswarlu, N. Ganji, S. Daravath, K. Kanneboina, K. Rangan, Shivaraj, Polyhedron 2019, 171, 86-97. https://doi.org/10.1016/j.poly.2019.06.048

[31] V. Sumalatha, A. Rambabu, N. Vamsikrishna, N. Ganji, S. Daravath, Shivaraj, Chem. Data Collect. 2019, $20,1$.

https://doi.org/10.1016/j.cdc.2019.100213 